\title{
Influence of delayed sample processing on blood immune cell phenotypes, immune cell responses and serum anti- influenza vaccine antibody titres
}

Vivian Castro-Herrera ${ }^{1, *}$, Mark Lown ${ }^{2}$, George Lewith ${ }^{2, \neq}$, Elizabeth A. Miles ${ }^{1}$, Philip C. Calder ${ }^{1,3}$

${ }^{1}$ Human Development and Health Academic Unit, Faculty of Medicine, University of Southampton, Southampton SO16 6YD, United Kingdom

${ }^{2}$ Primary Care and Population Sciences Academic Unit, Faculty of Medicine, University of Southampton, Southampton SO16 6YD, United Kingdom

${ }^{3}$ NIHR Southampton Biomedical Research Centre, University Hospital Southampton NHS Foundation Trust and University of Southampton, Southampton SO16 6YD, United Kingdom

*Author for correspondence: Vivian Castro-Herrera, Human Development and Health Academic Unit, Faculty of Medicine, University of Southampton, IDS Building MP887 Southampton General Hospital, Tremona Road, Southampton SO16 6YD, United Kingdom; Email:vmch1m14@soton.ac.uk

${ }^{\ddagger}$ Deceased 


\begin{abstract}
Provision of blood from distant research partners to a central laboratory can result in delayed blood processing prior to assessment of immune parameters. It is important to evaluate the effect of such delays on immune parameters. This study investigated the effect of storage of blood at room temperature for up to 72 hours prior to processing and analysis on a range of immune parameters. Blood was collected from 10 healthy participants and analysed immediately (day 0 ) or after storage at room temperature for 24,48 or 72 hours (days 1, 2 and 3). A full blood count, immune cell phenotypes (flow cytometry), plasma cytokines, chemokines and soluble receptors (multiplex immunoassay), neutrophil and monocyte phagocytosis (flow cytometry), whole blood cytokine responses to stimulation and antibody titres to the seasonal influenza vaccine were assessed. The full blood count, most immune cell phenotypes, monocyte phagocytosis and anti-influenza vaccine antibody titres were little affected by blood storage of $\leq 72$ hours prior to processing. Plasma cytokine concentrations increased with blood storage time while whole blood responses to stimulation with lipopolysaccharide or phytohaemagglutinin decreased with blood storage time. In conclusion, while fresh blood is optimal for analysing human immune parameters, it is possible to store blood for up to 72 hours at room temperature and obtain reliable measures of several immune markers. However, plasma cytokines and related mediators as well as whole blood cultures should be analysed using freshly isolated blood. Storage of blood for longer than one day may result in the unreliable assessment of these outcomes.
\end{abstract}




\section{Highlights}

- Large, multicentre or field studies of the human immune system may require blood to be stored for periods up to several days prior to analysis. The effects of such storage on subsequent analysis are not clear. Hence we studied a number of immune parameters in freshly isolated blood and in different sets of blood stored for up to 72 hours.

- The full blood count, most immune cell phenotypes, monocyte phagocytosis and antiseasonal influenza vaccine antibody titres were little affected by blood storage of up to 72 hours prior to processing. In contrast, plasma cytokine concentrations increased with blood storage time while whole blood responses to stimulation with lipopolysaccharide or phytohaemagglutinin decreased with blood storage time.

- Whilst fresh blood is the best option for analysing human immune parameters, it is also possible to store blood for up to 72 hours at room temperature and obtain reliable measures of several immune markers.

- Analyses for both, plasma cytokines and related mediators should be conducted and whole blood cultures should be performed using freshly isolated blood. Storage of blood for longer than one day may result in the unreliable assessment of these outcomes.

Key words: Delayed sample processing, T cell, phagocytosis, seasonal influenza vaccination, cytokine, adhesion molecules. 


\section{Introduction}

In human studies, the most practical tissue for the study of the immune system is usually blood. Immunological studies are commonly conducted by assessing blood immune cell phenotypes and immune cell responses ex vivo (Albers, Antoine, Bourdet-Sicard et al., 2007; Albers, Bourdet-Sicard, Braun et al., 2013). Many studies of immune function in humans, particularly large or complex studies, require collaboration between different sites or are conducted at locations distant from well-equipped laboratories. Such situations are characterised by a collection of blood that impairs processing or prompt analysis fresh, and which may need to be transported to a distant central laboratory for analysis according to a standardised protocol. This will likely delay the analysis by many hours or even days. It is not clear what the effect of such a delay may have on immune parameters that are commonly assessed in human studies. This study aimed to determine the effect of storage of blood at room temperature for up to 72 hours after collection on a range of immune parameters. The following were assessed: full blood count ( $F B C)$, immune cell phenotypes, plasma cytokines, neutrophil and monocyte phagocytosis of $E$. coli, whole blood cytokine responses to stimulation with toll-like receptor (TLR) 2, TLR4 and T-cell receptor agonists, and antibody titres to the seasonal influenza vaccine.

\section{Materials and methods}

\subsection{Participants}

This study had ethical approval From the Southampton Research Biorepository Access Committee (12/NW/0794) and used anonymised human blood samples from 10 healthy participants provided by the Southampton Research Biorepository. Participants provided written informed consent under the principles of the Declaration of Helsinki. Inclusion criteria were: age $>18$ years, body mass index between 18.5 and $35 \mathrm{~kg} / \mathrm{m}^{2}$, and having received the most recent seasonal influenza vaccine. Exclusion criteria were: pre-existing chronic disease, malignancy or an autoimmune disorder. 


\subsection{Sample handling and overview of analyses performed}

The Southampton Research Biorepository provided a total of $60 \mathrm{ml}$ of blood per participant. Samples were provided as multiple aliquots of blood collected into EDTA as an anticoagulant, into lithium heparin as an anticoagulant, and as whole blood which was allowed to clot. Blood samples from all participants were analysed at four separate time points. One set of analyses were performed within the first hour after blood collection from the participant (fresh analyses or day 0). Then the same set of analyses were performed using blood stored at room temperature (approximately $20^{\circ} \mathrm{C}$ ) and protected from light for 24,48 and 72 hours after collection (day 1, 2 and 3, respectively).

Samples collected into the tube containing EDTA as an anticoagulant was used to perform the full blood count (FBC). Samples collected into the tube containing heparin as anticoagulant were used to analyse blood immune cell phenotypes, phagocytic activity of neutrophils and monocytes, and cytokine and chemokine concentrations in plasma and in whole blood cultures after stimulation with lipopolysaccharide (LPS) from E. coli K12 strain (InVivoGen, San Diego, USA), phytohaemagglutinin (PHA-P) from Phaseolus vulgaris (red kidney bean) (Sigma-Aldrich, St Louis, USA) or peptidoglycan (PGN) from Staphylococcus aureus (InVivoGen, San Diego, USA). Samples collected without anti-coagulant were centrifuged at $1500 \mathrm{rpm}$ for 10 minutes to obtain serum samples which were used to analyse anti-influenza vaccine antibody titres.

\subsection{Analyses performed}

\subsubsection{Full blood count (FBC)}

FBC (numbers of white blood cells, lymphocytes, monocytes, neutrophils, eosinophils, basophils, platelets and red blood cells) was performed using an automated UniCel Beckman Coulter Dxl 800 (Beckman Coulter, High Wycombe, UK). 


\subsubsection{Anti Influenza vaccine antibodies}

Anti seasonal influenza vaccine antibodies were measured using the haemagglutination inhibition assay (HAI) (Defang, Martin, Burgess et al., 2012) which was conducted at Public Health England Colindale (London, UK).

\subsubsection{Analysis of peripheral blood immune phenotypes}

Flow cytometry through the staining panel design (Table 1 ) was used to identify T cells $\left(\mathrm{CD}^{+}\right)$, helper $\mathrm{T}$ cells $\left(\mathrm{CD}^{+} \mathrm{CD}^{+}\right)$, cytotoxic $\mathrm{T}$ cells $\left(\mathrm{CD}^{+} \mathrm{CD} 8^{+}\right)$, suppressor $\mathrm{T}$ cells $\left(\mathrm{CD}^{+}{ }^{+} \mathrm{CD} 8^{+} \mathrm{CD} 25^{+}\right)$, regulatory T cells $\left(\mathrm{CD} 3^{+} \mathrm{CD} 4^{+} \mathrm{CD} 8^{-} \mathrm{CD} 25^{\mathrm{hi}} \mathrm{CD} 127^{\text {lo }}\right)$, B cells $\left(\mathrm{CD} 19^{+} \mathrm{CD} 80^{+}\right.$and $\left.\mathrm{CD}_{19}{ }^{+} \mathrm{CD} 86^{+}\right)$, monocytes $\left(\mathrm{CD} 14^{+}\right)$and NK cells $\left(\mathrm{CD} 3^{-} \mathrm{CD} 16^{+}\right)$. Additionally, the fluorescence intensity of CD14 expression on monocytes and neutrophils was analysed.

Heparinised whole blood $(100 \mu \mathrm{l})$ was placed in FACS tubes as controls or containing bright beads (BD Trucount ${ }^{\mathrm{TM}}$ tubes; BD Pharmingen, Oxford, UK). Brilliant violet buffer (50 $\mu \mathrm{l}$; BD Pharmingen, Oxford, UK) was added, followed by the antibodies selected to stain specific cell subtypes (full details of the antibodies used are given in Table 1). All antibodies were purchased from BD Pharmingen (Oxford, UK). Staining was performed at room temperature for 15 to 20 minutes and protected from light. BD-FACS Lysing solution $(1 \mathrm{ml}$; BD Pharmingen, Oxford, UK) was added to each tube. Complete lysis of red cells occurred after 20 minutes. Tubes were kept at room temperature in the dark overnight and were analysed within 18 hours on a BD FACS LSRF Fortessa ${ }^{\mathrm{TM}}$ X-20 Special order (BD Biosciences, San Jose, CA). The absolute number of cells was determined by comparing cellular events to Trucount bead events. Isotype controls were run at a medium flow rate and 10,000 events were collected for all samples analysed. Negative or non-stained control was performed in a tube without beads. The staining panel was performed in the tubes containing Trucount beads. The beads were gated and 5,000 events were collected within the bead region. Data analyses were performed with BD FACSDiva 8.0.1 software and FlowJo, LLC Single Cell Analysis Software v10. Instrument stability was checked daily using the cytometer setup and tracking (CST) to evaluate performance by using CS\&T Research Beads ${ }^{\mathrm{TM}}$ (BD Biosciences, Oxford, UK).

\subsubsection{Phagocytic activity of neutrophils and monocytes}


Phagocytic activity of blood neutrophils and monocytes was assessed using the commercially available Phagotest ${ }^{\mathrm{TM}}$ kit (Glycotope Biotechnology $\mathrm{GmbH}$, Heidelberg Germany), based upon uptake of fluorescein isothiocyanate (FITC) labelled E. coli which were measured using flow cytometry. The assay was conducted according to the manufacturer's instructions. At the end of the assay, a total of 20,000 events were collected for each tube using a BD FACSCalibur flow cytometer (BD Biosciences, San Jose, CA). Both the proportion of cells (granulocytes, mainly neutrophils, and monocytes) involved in phagocytosis and their mean fluorescence intensity (indicating the number of ingested bacteria per cell) were analysed.

\subsubsection{Cytokines, immune mediators and soluble receptors in plasma}

The following cytokines, immune mediators and soluble receptors were measured in plasma: tumour necrosis factor (TNF)- $\alpha$, interleukin (IL)-6, IL-8, IL-10, IL-18BPa, IL-1 receptor antagonist (IL-1ra; also known as IL-1F3), TNF receptor 2 (TNFRII), monocyte chemoattractant protein 1 (MCP-1; also known as CCL2), macrophage inflammatory protein (MIP-1 $\alpha$; also known as CCL3), regulated on activation, normal T cell expressed and secreted (RANTES; also known as CCL5), soluble intracellular adhesion molecule 1 (ICAM-1; also known as soluble CD54), soluble vascular cell adhesion molecule 1 (VCAM-1; also known as soluble CD106), and soluble E-Selectin (also known as soluble CD62E). Plasma samples were kept at $-20^{\circ} \mathrm{C}$ for a maximum of 8 months prior to analysis. Immune mediators and soluble receptors were measured by Bio-Techne multiplex immunoassay (R\&D Systems, Abingdon, UK). Reagents were brought to room temperature before use and dilutions were prepared immediately before use according to the manufacturer's instructions. The microparticles were resuspended in buffer and read using a Bio-Rad-plex Luminex Analyzer. Lower limits of detection (pg/mL) were: TNF- $\alpha$ (0.8), IL-6 (1.0), IL-8 (0.8), IL-10 (0.5), IL-18BPa (1.9), IL-1ra (16.9), TNFRII (6.2), MCP-1 (3.3), MIP-1 $\alpha$ (16.0), RANTES (1.8), ICAM-1 (87.9), VCAM-1 (238) and E-selectin (7.4). 


\subsubsection{Whole Blood cultures and immune mediators}

Heparinised whole blood was diluted 1:10 in RPMI 1640 culture medium supplemented with penicillin $(50 \mathrm{U} / \mathrm{mL})$, streptomycin $(50 \mathrm{ug} / \mathrm{mL})$ and L-glutamine $(2 \mathrm{mM})$ (Sigma Aldrich, Gillingham, UK). Diluted blood (990 ul) was added to the wells of a 24-well flat-bottomed cell culture plate. Then, $10 \mu \mathrm{L}$ of either medium, LPS, PGN or PHA was added to the wells to obtain final concentrations of $10 \mathrm{ug} / \mathrm{ml}$ LPS, $5 \mathrm{ug} / \mathrm{ml}$ PHA or $5 \mathrm{ug} / \mathrm{ml}$ PGN, respectively. Cultures were incubated for 24 hours at $37^{\circ} \mathrm{C}$ in an atmosphere of $95 \%$ air and $5 \% \mathrm{CO}_{2}$. Supernatants were collected by centrifuging the plates at $2000 \mathrm{rpm}$ for 5 minutes and were then stored at $-80^{\circ} \mathrm{C}$ for analysis within a maximum timeframe of 9 months. Once all supernatants were ready to be analysed, Bio-Techne Magnetic Luminex assays (R\&D systems, Abingdon, UK) were used. Analytes measured in negative controls and in the medium after stimulation with PGN or LPS and the assay limits of detection $(\mathrm{pg} / \mathrm{ml})$ were: TNF- $\alpha$ (1.2), IL-1 $\beta$ (0.8), IL-6 (1.7), IL-10 (1.6) and IL-12p70 (20.2). Analytes measured in negative controls and in the medium after stimulation with PHA were TNF- $\alpha$ (limit of detection (pg/ml) 0.54), IFN- $\gamma$ (0.02), IL-2 (0.28), IL-4 (2.54), IL-5 (0.12) and IL-13 (2.01). Assays were performed according to the manufacturer's instructions. The microparticles were resuspended in buffer and read using a Bio-Rad-plex Luminex Analyzer.

\subsubsection{Statistical analysis}

Normality of data was assessed by visual inspection of histogram distributions and by using the Shapiro Wilk and Kolmogorv-Smirnov tests. Most data were not normally distributed. Normally distributed data are described as a mean and standard error. Not normally distributed data are described as a median and interquartile range. The significance of differences across time (of blood storage) was assessed using the related-samples Friedman's test. Where Friedman's test indicated a significant effect of time, pairwise comparisons using nonparametric tests were performed. Data collation and analysis were performed in SPSS version 22 (IBM Corp., Armonk, New York) and Excel. In all cases, statistical significance is indicated by a value of $p<0.05$. 


\section{Results}

\subsection{Full Blood Count}

Lymphocyte, monocyte, eosinophil, basophil platelet and erythrocyte numbers did not differ according to the time of blood storage prior to analysis (Table 2). In contrast, there was a significant effect of storage time on total leukocyte and neutrophil numbers, with cell number declining with increasing storage time (Table 2). Pairwise analysis revealed significantly lower leukocyte numbers at days 2 and 3 compared with day $1(p=0.012)$. Neutrophil numbers were significantly lower at day 3 compared with day $1(p=0.012)$.

\subsection{Seasonal influenza vaccine}

Anti-influenza vaccine antibody titres were not significantly affected by storage time of blood before analysis (Table 3).

\subsection{Immune cell phenotypes}

The numbers of $\mathrm{T}$ lymphocytes $\left(\mathrm{CD}^{+}\right)$, helper $\mathrm{T}$ lymphocytes $\left(\mathrm{CD} 3^{+} \mathrm{CD} 4^{+}\right)$, supressor $\mathrm{T}$ lymphocytes $\left(\mathrm{CD}^{+} \mathrm{CD}^{+}\right)$, regulatory $\mathrm{T}$ lymphocytes $\left(\mathrm{CD}^{+} \mathrm{CD} 4^{+} \mathrm{CD} 25^{+\mathrm{H}} \mathrm{CD} 127^{\mathrm{LO}}\right), \quad \mathrm{B}$ lymphocytes $\left(\mathrm{CD} 19^{+}\right)$, and monocytes $\left(\mathrm{CD} 14^{+}\right)$were not significantly affected by blood storage time (Table 4). The geometric mean for the fluorescence intensity of CD14+ of monocytes and neutrophils was not altered by blood storage time (data not shown).

Time of blood storage prior to immunophenotyping significantly affected numbers of natural killer cells $\left(\mathrm{CD}^{-} \mathrm{CD}^{-} 6^{+}\right)$(Table 4) with cells/ul being significantly lower at days 2 $(p=0.002)$ and $3(p<0.05)$ compared with day 0 . The numbers of activated suppressor $T$ cells $\left(\mathrm{CD}^{+} \mathrm{CD}^{+} \mathrm{CD} 25^{+}\right)$were significantly lower in the blood on day 3 compared with blood on day $0(p=0.003)$. Relative expression of CD14 (geometric mean) was not significantly affected by delayed blood processing for neutrophils or for monocytes.

\subsection{Phagocytic activity of neutrophils and monocytes}


The percentage of neutrophils and monocytes engaging in phagocytosis did not change according to the storage time of blood prior to analysis (Table 5). Likewise, the phagocytic activity of monocytes assessed as fluorescence intensity (representing engulfed labelled bacteria) did not differ according to storage time (Table 5). However, phagocytic activity assessed in neutrophils (i.e. fluorescence intensity) was affected by storage time (Table 5). This was due to decreased activity in blood on day 3 compared with day $0(p=0.002)$.

\subsection{Cytokines and immune mediators and soluble receptors in plasma}

Plasma concentrations of all the immune mediators measured, except for ICAM-1, were significantly affected by the time of blood storage prior to processing (Table 6). The concentrations of MCP-1, RANTES, TNF-RII, IL-1ra, E-selectin, IL-18BPa, IL-8 and IL-10 increased with blood storage time, with the result that concentrations at days 2 and/or 3 were significantly higher than those at days 0 and/or 1 (Table 6). This was most pronounced for concentrations of TNF- $\alpha$, IL-1ra, IL-6, IL-8 and IL-10. The concentration of MIP-1 $\alpha$ was higher at days 1 and 2 compared with day 0 . In contrast, the plasma concentration of VCAM1 was significantly lower at day 3 when compared to the concentration at days 0 and 1 .

\subsection{Whole blood cultures and immune mediators}

From TNF- $\alpha$ and IL-6 detected in the supernatants of unstimulated whole blood cultures, TNF- $\alpha$ concentration increased with time of blood storage with TNF- $\alpha$ production is significantly higher in blood cultured on day 3 compared with day $0(p=0.019)$ and in blood cultured on day 3 compared with day $1(p=0.010)$.

All five immune mediators analysed were detectable in the supernatants of whole blood stimulated with PGN or LPS. Of the immune mediators analysed in the supernatants of whole blood stimulated with PHA only two, TNF- $\alpha$ and IFN- $\gamma$, were detectable.

The concentration of TNF- $\alpha$ in the supernatant of whole blood cultures stimulated with PGN was significantly affected by time of blood storage (Table 7). It was higher in blood cultured 
at day 2 or 3 compared with that cultured on day 0 (Table 7). The concentrations of IL-1 $\beta$ and IL-12 also tended to increase in these cultures.

The concentrations of all five cytokines (IL-10, TNF- $\alpha$, IL-6, IL-12p70, IL-1 $\beta$ ) in the supernatants of whole blood cultures stimulated with LPS were affected by time of blood storage prior to culture (Table 7). Overall, the concentration of each of these cytokines decreased with time of blood storage, such that they were lower in blood cultured on day 3 than on day 0 (Table 7). IL-10, IL-12p70 and IL-1 $1 \beta$ concentrations were also significantly lower in blood cultured on day 2 compared with that cultured on day 0.

The concentrations of both TNF- $\alpha$ and IFN- $\gamma$ in the supernatants of whole blood cultures stimulated with PHA were affected by time of blood storage prior to culture (Table 7). The concentration of both of these cytokines decreased with time of blood storage, such that they were lower from blood cultured on days 1 and 2 than blood cultured on day 0 (Table 7).

\section{Discussion}

Access to fresh samples for the assessment of immune function may be limited in some experimental settings. These include when a multi-centre study is performed and there is a single laboratory involved in the immune function assessment and when studies are conducted in settings distant from the analytical laboratory. Consequently, sample processing might be delayed for a period ranging from hours to several days. Therefore, it is important to understand the impact of such a delay in carrying out the immune assessments. In this study, we collected blood from ten healthy subjects. These analyses reveal the usability of blood samples stored at a room temperature (approximately $20^{\circ} \mathrm{C}$ ), sunlight protected and for up to 72 hours for some assays. Additionally, the findings also suggest that some of the analyses must be performed on fresh samples in order to generate reliable data. 
The methods studied here are practical and applicable in immunological focused research intending to analyse human blood samples. We assessed immune cells in blood by quantification (full blood count) and also as different immune cell phenotypes providing insight into the effect of delayed processing. We also analysed plasma immune mediator concentrations, phagocytic responses of neutrophils and monocytes, cytokine production of whole blood cultures in response to three different stimuli, and serum anti-seasonal influenza vaccine antibody titres. These are all commonly measured immune outcomes in human studies (Albers et al., 2007; Albers et al., 2013). From these analyses, the most stable results were observed for the anti-influenza vaccine antibodies titres, which were not altered by blood storage in this study.

Delayed storage in this study had variable effects on the immune cell numbers obtained from the full blood count. The leukocyte numbers showed a significant reduction over time with the numbers in blood at days 3 and 4 being significantly lower than in blood at day 1 . This reduction in leukocyte number was the result of a significant decrease in the neutrophil number. The lack of significant change in lymphocyte and monocyte numbers from the full blood count was confirmed by immune phenotyping using antibodies to surface makers. Numbers of several other immune cell subtypes were stable with blood storage, but the number of natural killer cells and activated suppressor T cells decreased with blood storage. Kwan et al. reported that overnight storage of heparinized whole blood at room temperature reduced natural killer cell cytotoxic activity (Kwan, Roberts, Ank et al., 1996). We did not assess natural killer cell activity but our observation of decreased natural killer cell numbers in the stored blood may account for the findings of Kwan et al. alternatively, both natural killer cell numbers and activity may decrease with blood storage.

In this study $\mathrm{T}$ helper and $\mathrm{T}$ suppressor cell numbers were not significantly changed by delayed analysis which is consistent with the findings from other studies. Thornthwaite et al determined the percentages of $\mathrm{T}$ helper and $\mathrm{T}$ suppressor lymphocytes from human blood stored over 4 days at room temperature and reported no significant changes (Thornthwaite, Rosenthal, Vazquez et al., 1984). We assessed total cell numbers, but it seems likely that percentages of these cells would also not be different in blood stored for several days prior to analysis. 
The concentration of many cytokines and related immune mediators in plasma increased with longer time of blood storage. In contrast, the production of several cytokines by whole blood cultures in response to LPS was significantly decreased if blood was stored prior to culture. A similar effect was seen for TNF- $\alpha$ and IFN- $\gamma$ production in response to PHA, a Tcell stimulant. The observed increase in the concentration of many cytokines in plasma with longer time of blood storage prior to plasma preparation may be because cells continued to produce cytokines during storage of the blood. Our findings may be compared with those from a previous study also looking at the effect of storage time on immune mediators in plasma. Jackman et al. (2011) investigated the effect of blood sample storage on the measured concentrations of 41 immune mediators. Like us, they prepared plasma fresh or from blood stored for one, two or three days; blood came from ten healthy subjects. Immune mediators were measured in plasma by Multiplex. The concentrations of nine mediators increased significantly over the four day period. These included IL-1ra and IL-8 which increased by $278 \%$ and $152 \%$ per day, respectively (Jackman, Utter, Heitman et al., 2011). Qualitatively our findings agree with these observations on plasma cytokine concentrations, but Jackman et al. (2011) did not investigate the other immune parameters reported in the current study.

It is possible that leukocytes in the blood were already activated in vivo and continued to produce or release cytokines in the stored blood. Alternatively, the cells may have become activated during the storage process either as a result of the cell to cell contact or because of depletion of nutrients or the production of toxic products. A final possibility is that as a result of cell death in stored blood, intracellular proteins were released into the plasma. Our results show that neutrophil numbers declined significantly by $72 \mathrm{hrs}$. Neutrophils produce a wide range of cytokines, chemokines and other inflammatory molecules. Furthermore, in addition to producing these molecules, they store quantities of inflammatory molecules which may be released during cell death (Tecchio, Micheletti, \& Cassatella, 2014). This might account, at least in part, for our observations. 
In contrast to what was seen in the plasma isolated from stored blood, whole blood cultured with LPS produced lower concentrations of cytokines if it had been stored for longer prior to culture. In such cultures, it is neutrophils and monocytes that are responsible for cytokine production in the presence of LPS as both cell types express the required receptor, TLR4. Signalling through TLR4 by LPS also requires CD14 (Plociennikowska, Hromada-Judycka, Borzecka et al., 2015). Our results showed that delayed processing reduced cytokine production in response to LPS suggesting the responsible cells were reduced in numbers or responsiveness to LPS stimulation. Our data show that delayed processing resulted in a reduction in the number of neutrophils in the samples by day 2 . This decrease in neutrophil number may result in reduced cytokine production in response to LPS. Phagocytic activity of neutrophils in response to $E$. coli was also reduced with delayed blood processing although the percentage of neutrophils engaged in phagocytosis did not change. The decline in responsiveness to LPS which is mediated through the TLR4 and CD14 receptors for both the cytokine and phagocytic response may suggest an alteration in the expression or function of these two receptors. We did not assess the relative levels of expression of TLR4, but we did measure the relative expression of CD14 on the monocyte and neutrophil populations. The relative expression of CD14 did not change significantly on the neutrophils or monocytes with delayed blood processing. This suggests that reduced TLR4 expression or reduced TLR4 and/or CD14 function may be an alternative explanation for the reduced neutrophil response to LPS.

Another possible explanation is that in the stored blood, prior to culture, cells were activated and producing cytokines. This would explain the increase in plasma cytokine concentrations with blood storage. The continued stimulation of the stored blood could result in the cells being less responsive to stimulation when exposed to LPS in culture (Kohler \& Joly, 1997). We did not assess this, but this phenomenon has been described as "immune exhaustion". This can lead to negative feedback, for example, inhibition of monocyte nuclear factor kappa B activation (Bohuslav, Kravchenko, Parry et al., 1998; LaRue \& McCall, 1994). Therefore, when the cells are re-stimulated in the culture they are less responsive. 
We saw similar findings in the PHA-stimulated cultures. These cultures showed a significant reduction in TNF- $\alpha$ and IFN- $\gamma$ production by day 3 of blood storage. PHA is a mitogen used to stimulate $\mathrm{T}$ lymphocytes. This result suggests that, although $\mathrm{T}$ cell and $\mathrm{T}$ cell subtype numbers did not significantly decline with delayed blood processing, $\mathrm{T}$ cell cytokine production in response to PHA was affected, indicating that T cells become less active.

Stimulation with PGN, which is a TLR2 ligand and would stimulate neutrophils and monocytes, did not fit the pattern seen with the LPS and PHA stimulated cultures. In this study, the cytokines produced by PGN-stimulated cultures did not change with delayed blood storage with the exception of TNF- $\alpha$ production which significantly increased by day 3 . These results suggest that although cytokine production in response to stimulation via TLR4 with LPS was adversely affected by delayed processing, production in response to stimulation through TLR2 was not.

Although we have investigated the effect of blood storage time on immune cell phenotypes and responses, we did not examine other storage factors that could have an effect on immune parameters such as changing the temperature of blood storage and agitation. Further evaluation regarding these other conditions of storage might be useful. For example, room temperature in the current study was about $20^{\circ} \mathrm{C}$, but in other settings it may be higher (or lower) than this, while storage of blood in a refrigerator or shipment of blood samples on ice prior to processing may also be possibilities in some settings. The effect of blood storage at different temperatures prior to processing should be tested.

The analysis of lymphocyte proliferation is a commonly used measure of immune cell function, being usually assessed following exposure of whole blood or isolated cells to a Tcell stimulant like PHA. We did not use this assay in the current study and so are unable to comment on its stability to blood storage time. However, we did assess cytokine responses to PHA stimulation and found these to decrease with prolonged blood storage. This suggests that the proliferative response of T-cells would also be decreased if analysed using blood stored for one day or more. However, this should be tested. 
Our findings suggest that immune cell numbers and subsets, serum influenza vaccine antibody concentrations, and phagocytosis can be assessed using blood stored for up to 48 hours prior to processing or perhaps even longer for some measures. In contrast, for a number of immune mediators produced in whole blood cultures in response to commonly used immune stimulants like PGN, LPS and PHA blood storage should be limited to $<24$ hours prior to culture. The measurement of immune mediators and soluble receptors in the plasma produced from heparinised blood must be performed using plasma prepared from the blood on the day of collection for the outcome to be reliable.

\section{Conclusions}

In conclusion, fresh blood is the best option to perform analyses related to immune outcomes in humans. This is critical in the study of plasma cytokines and related mediators which should be measured (and whole blood cultures should be performed) using freshly isolated blood. Storage of blood for longer than one day will result in the unreliable assessment of these outcomes. Nevertheless, it is possible to store blood for a few days and to obtain reliable measures of several immune markers.

\section{Acknowledgements}

VC-H is supported by Colciencias, Colombia. 
Table 1. Antibodies used to identify immune cell populations in blood.

\begin{tabular}{|c|c|c|c|}
\hline $\begin{array}{l}\text { Immune cell } \\
\text { population }\end{array}$ & $\begin{array}{l}\mathrm{CD} \text { or combination of } \mathrm{CD} \text { used to } \\
\text { identify the population }\end{array}$ & Fluorochrome used & $\begin{array}{ll}\mu \mathrm{L} & \text { of } \\
\text { antibody } & \\
\text { used/test } & \end{array}$ \\
\hline T cells & $\mathrm{CD}^{+}$ & AF647 & 5 \\
\hline Helper T cells & $\mathrm{CD}^{+} \mathrm{CD}^{+}$ & AF647/AF488 & $5 / 5$ \\
\hline Cytotoxic T cells & $\mathrm{CD}^{+} \mathrm{CD}^{+}$ & AF647/AF488 & $5 / 5$ \\
\hline Regulatory T cells & $\mathrm{CD}^{+}{ }^{+} \mathrm{CD} 4^{+} \mathrm{CD} 8^{-} \mathrm{CD} 25^{\mathrm{HI}} \mathrm{CD} 127^{\mathrm{LO}}$ & AF647/AF488/PE/BV421 & $5 / 5 / 5 / 20 / 5$ \\
\hline Suppressor T cells & $\mathrm{CD}^{+} \mathrm{CD} 8^{+} \mathrm{CD} 25^{+}$ & AF647/AF488/PE & $5 / 5 / 20$ \\
\hline Monocytes & $\mathrm{CD}_{14}^{+}$ & AF488 & 5 \\
\hline Activated monocytes & $\mathrm{CD} 14^{+} \mathrm{CD} 80^{+}$ & AF488/BV421 & $5 / 5$ \\
\hline Activated monocytes & $\mathrm{CD} 14^{+} \mathrm{CD} 6^{+}$ & $\mathrm{AF} 488 / \mathrm{PE}$ & $5 / 20$ \\
\hline B cells & $\mathrm{CD}^{-} \mathrm{CD} 19^{+}$ & AF647/AF488 & $5 / 5$ \\
\hline Activated B cells & $\mathrm{CD}^{-} \mathrm{CD}^{-} 9^{+} \mathrm{CD} 80^{+}$ & AF647/AF488/BV421 & $5 / 5 / 5$ \\
\hline Activated B cells & $\mathrm{CD}^{-} \mathrm{CD} 19^{+} \mathrm{CD} 86^{+}$ & AF647/AF488/PE & $5 / 5 / 20$ \\
\hline Natural killer cells & $\mathrm{CD}^{-} \mathrm{CD} 16^{+}$ & AF647/PE & $5 / 20$ \\
\hline
\end{tabular}

AF647 = Alexa Fluor 647 Mouse Anti-Human CD3 ${ }^{+}$; AF488 = Alexa Fluor 488 Mouse Anti-Human CD8 ${ }^{+}$; $\mathrm{PE}=$ Phycoerythrin; FITC $=$ Fluorescein isothiocyanate; BV421= Mouse Anti- Human 
Table 2. Full blood count of blood samples analysed immediately (day 0 ) or after storage of blood at room temperature for 24, 48 or 72 hours (day 1, 2 and 3, respectively) prior to analysis. Data are median (IQR) for $\mathrm{n}=10$ per time point. $\mathrm{P} 10$ and $\mathrm{p} 90$ represent $10^{\text {th }}$ and $90^{\text {th }}$ percentile values. $\mathrm{P}$ value is for the Friedman's test. Where pairwise comparisons were made, median values not sharing a common letter are different.

\begin{tabular}{|c|c|c|c|c|c|c|c|}
\hline $\begin{array}{c}\text { FBC } \\
\text { parameter }\end{array}$ & Units & Descriptor & Day 0 & Day 1 & Day 2 & Day 3 & $p$ value \\
\hline \multirow{4}{*}{$\begin{array}{l}\text { Total white } \\
\text { cell count } \\
\text { (WBC) }\end{array}$} & \multirow[t]{4}{*}{$10^{9} / \mathrm{L}$} & Median & $5.90^{\mathrm{ac}}$ & $5.95^{\mathrm{a}}$ & $5.75^{\mathrm{bc}}$ & $5.55^{\mathrm{bc}}$ & \multirow[t]{4}{*}{0.035} \\
\hline & & IQR & 3.00 & 3.00 & 3.10 & 3.10 & \\
\hline & & $\mathrm{p} 10$ & 3.61 & 3.62 & 3.52 & 3.61 & \\
\hline & & p90 & 9.37 & 9.54 & 9.56 & 9.52 & \\
\hline \multirow[t]{4}{*}{ Neutrophils } & \multirow[t]{4}{*}{$10^{9} / \mathrm{L}$} & Median & $3.25^{\mathrm{ab}}$ & $3.25^{\mathrm{a}}$ & $3.15^{\mathrm{ab}}$ & $3.10^{\mathrm{b}}$ & \multirow[t]{4}{*}{0.045} \\
\hline & & IQR & 1.88 & 1.73 & 1.98 & 1.95 & \\
\hline & & p10 & 1.85 & 1.93 & 1.84 & 1.65 & \\
\hline & & p90 & 6.53 & 6.70 & 6.26 & 6.51 & \\
\hline \multirow[t]{4}{*}{ Lymphocytes } & \multirow[t]{4}{*}{$10^{9} / \mathrm{L}$} & Median & 1.80 & 1.80 & 1.90 & 1.70 & \multirow[t]{4}{*}{0.087} \\
\hline & & IQR & 0.95 & 0.98 & 0.98 & 0.97 & \\
\hline & & $\mathrm{p} 10$ & 1.01 & 1.00 & 1.00 & 1.00 & \\
\hline & & p90 & 2.20 & 2.38 & 2.29 & 2.29 & \\
\hline \multirow[t]{4}{*}{ Monocytes } & \multirow[t]{4}{*}{$10^{9} / \mathrm{L}$} & Median & 0.40 & 0.45 & 0.40 & 0.40 & \multirow[t]{4}{*}{0.869} \\
\hline & & IQR & 0.13 & 0.20 & 0.23 & 0.20 & \\
\hline & & p10 & 0.21 & 0.21 & 0.21 & 0.30 & \\
\hline & & p90 & 0.68 & 0.59 & 0.78 & 0.68 & \\
\hline \multirow[t]{4}{*}{ Eosinophils } & \multirow[t]{4}{*}{$10^{9} / \mathrm{L}$} & Median & 0.15 & 0.20 & 0.15 & 0.15 & \multirow[t]{4}{*}{0.223} \\
\hline & & IQR & 0.20 & 0.30 & 0.20 & 0.20 & \\
\hline & & p10 & 0.01 & 0.01 & 0.01 & 0.01 & \\
\hline & & P90 & 0.40 & 0.40 & 0.39 & 0.39 & \\
\hline Basophils & $10^{9} / \mathrm{L}$ & Median & 0.00 & 0.00 & 0.05 & 0.05 & 0.300 \\
\hline
\end{tabular}




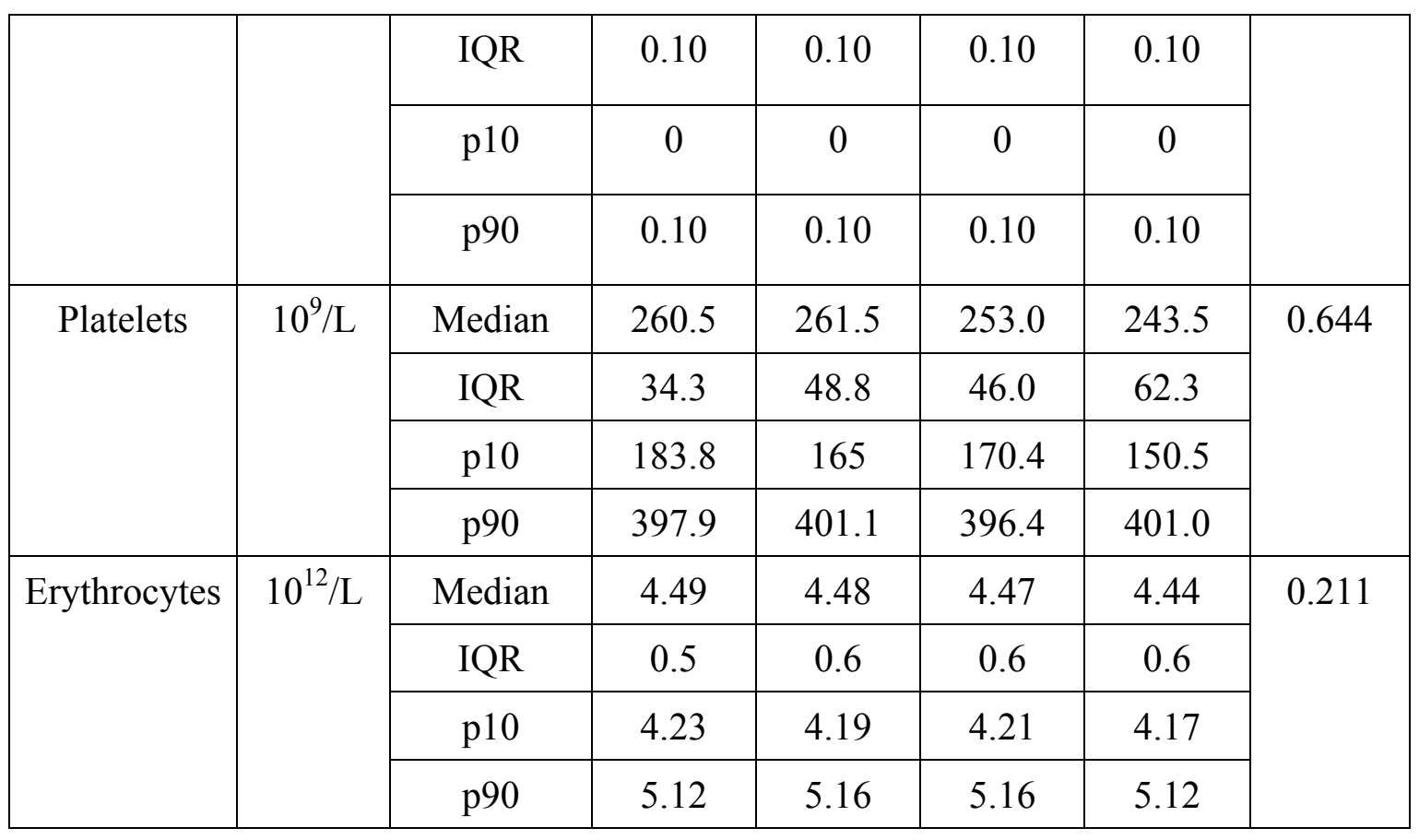


Table 3. Hemagglutination inhibition assay results. Serum was prepared and frozen immediately (day 0) or after blood storage at room temperature for 24,48 or 72 hours (day 1, 2 and 3, respectively) prior to serum preparation. Data are geometric mean titre, interquartile range (IQR), $10^{\text {th }}(\mathrm{P} 10)$ and $90^{\text {th }}(\mathrm{P} 90)$ percentile values for $\mathrm{n}=10$ per time point. $\mathrm{P}$ value is for the Friedman's test.

\begin{tabular}{|c|c|c|c|c|c|c|}
\hline Vaccine strain & Descriptor & Day 0 & Day 1 & Day 2 & Day 3 & p Value \\
\hline \multirow[t]{4}{*}{$\mathrm{H} 3 \mathrm{~N} 2$} & Geometric Mean & 130 & 130 & 139 & 149 & \multirow[t]{4}{*}{0.468} \\
\hline & IQR & 360 & 360 & 360 & 330 & \\
\hline & $\mathrm{p} 10$ & 40 & 40 & 40 & 40 & \\
\hline & p90 & 768 & 768 & 768 & 640 & \\
\hline \multirow[t]{4}{*}{ H1N1 } & Geometric Mean & 80 & 86 & 99 & 92 & \multirow[t]{4}{*}{0.112} \\
\hline & IQR & 263 & 260 & 260 & 260 & \\
\hline & $\mathrm{p} 10$ & 10 & 19 & 19 & 19 & \\
\hline & p90 & 640 & 640 & 704 & 704 & \\
\hline \multirow[t]{4}{*}{ B } & Geometric Mean & 226 & 243 & 226 & 243 & \multirow[t]{4}{*}{0.870} \\
\hline & IQR & 510 & 500 & 560 & 560 & \\
\hline & p10 & 40 & 76 & 76 & 76 & \\
\hline & p90 & 768 & 768 & 768 & 768 & \\
\hline
\end{tabular}


Table 4. Immune cell phenotypes (cells/ul) in blood samples analysed immediately (day 0) or after blood was stored at room temperature for 24, 48 or 72 hours (days 1, 2 and 3, respectively) prior to analysis. Data are median (IQR) for $\mathrm{n}=9$ per time point. $\mathrm{P} 10$ and $\mathrm{p} 90$ represent $10^{\text {th }}$ and $90^{\text {th }}$ percentile values. $\mathrm{P}$ value is from the Friedman's test. Where pairwise comparisons were made, median values not sharing a common letter are different.

\begin{tabular}{|c|c|c|c|c|c|c|}
\hline Immunophenotype & Descriptor & Day 0 & Day 1 & Day 2 & Day 3 & $\begin{array}{c}\mathbf{p} \\
\text { Value }\end{array}$ \\
\hline \multirow{4}{*}{$\mathrm{CD}^{+}$} & Median & 1342.4 & 1313.8 & 1208.1 & 1148.0 & \multirow{4}{*}{0.161} \\
\hline & IQR & 818.9 & 642.8 & 745.5 & 742.1 & \\
\hline & p10 & 782.6 & 835.5 & 8206 & 762.2 & \\
\hline & p90 & 1721.2 & 1649.4 & 1733.7 & 1706.3 & \\
\hline \multirow[t]{4}{*}{$\mathrm{CD}^{+} \mathrm{CD}^{+}$} & Median & 900.5 & 863.5 & 827.9 & 817.2 & \multirow[t]{4}{*}{0.586} \\
\hline & IQR & 562.0 & 454.4 & 537.9 & 529.0 & \\
\hline & $\mathrm{p} 10$ & 565.3 & 631.0 & 546.9 & 509.6 & \\
\hline & p90 & 1233.8 & 1172.7 & 1262.8 & 1260.5 & \\
\hline \multirow[t]{4}{*}{$\mathrm{CD}^{+} \mathrm{CD}^{+}$} & Median & 367.8 & 255.1 & 338.4 & 304.6 & \multirow[t]{4}{*}{0.137} \\
\hline & IQR & 255.4 & 286.3 & 288.3 & 263.8 & \\
\hline & p10 & 116.3 & 116.3 & 123.1 & 107.0 & \\
\hline & p90 & 504.5 & 527.7 & 507.9 & 463.9 & \\
\hline \multirow[t]{4}{*}{$\mathrm{CD}^{+} \mathrm{CD}^{+} \mathrm{CD} 25^{+}$} & Median & $316.2^{\mathrm{a}}$ & $220.8^{\mathrm{ab}}$ & $288.5^{\mathrm{a}}$ & $238.3^{\mathrm{b}}$ & \multirow[t]{4}{*}{0.020} \\
\hline & IQR & 182.7 & 211.9 & 228.2 & 205.9 & \\
\hline & p10 & 98.8 & 96.0 & 94.8 & 88.0 & \\
\hline & p90 & 391.8 & 410.2 & 419.6 & 376.5 & \\
\hline \multirow[t]{4}{*}{$\mathrm{CD}^{+} \mathrm{CD} 4^{+} \mathrm{CD} 8 \mathrm{CD} 25^{\mathrm{HI}} \mathrm{CD} 127^{\mathrm{LO}}$} & Median & 53.5 & 56.7 & 61.4 & 58.8 & \multirow[t]{4}{*}{0.996} \\
\hline & IQR & 39.6 & 22.5 & 36.8 & 31.2 & \\
\hline & p10 & 29.5 & 33.8 & 30.9 & 34.0 & \\
\hline & $\mathrm{P} 90$ & 83.1 & 76.1 & 84.5 & 74.8 & \\
\hline \multirow[t]{2}{*}{$\mathrm{CD}^{+}: \mathrm{CD}^{+}$} & Median & 2.6 & 3.1 & 2.8 & 3.1 & \multirow[t]{2}{*}{0.058} \\
\hline & IQR & 2.7 & 3.6 & 3.3 & 3.0 & \\
\hline
\end{tabular}




\begin{tabular}{|c|c|c|c|c|c|c|}
\hline & $\mathrm{p} 10$ & 1.6 & 1.5 & 1.3 & 1.7 & \\
\hline & p90 & 6.0 & 6.6 & 6.7 & 6.8 & \\
\hline \multirow[t]{4}{*}{$\mathrm{CD}^{-} \mathrm{CD}^{-} 9^{+}$} & Median & 370.0 & 390.3 & 378.6 & 366.0 & \multirow[t]{4}{*}{0.615} \\
\hline & IQR & 175.9 & 159.3 & 243.0 & 261.7 & \\
\hline & p10 & 202.9 & 302.9 & 221.5 & 208.0 & \\
\hline & p90 & 436.7 & 520.3 & 571.5 & 589.0 & \\
\hline \multirow[t]{4}{*}{$\mathrm{CD}^{-} \mathrm{CD} 19^{+} \mathrm{CD} 80^{+}$} & Median & 130.9 & 125.5 & 177.3 & 177.7 & \multirow[t]{4}{*}{0.769} \\
\hline & IQR & 131.0 & 259.3 & 227.2 & 275.0 & \\
\hline & p10 & 22.9 & 27.4 & 83.0 & 64.6 & \\
\hline & p90 & 209.4 & 343.9 & 426.2 & 395.8 & \\
\hline \multirow[t]{4}{*}{$\mathrm{CD}^{-} \mathrm{CD} 19^{+} \mathrm{CD}^{-} 6^{+}$} & Median & 123.0 & 117.4 & 150.3 & 161.3 & \multirow[t]{4}{*}{0.833} \\
\hline & IQR & 115.4 & 228.8 & 204.5 & 261.8 & \\
\hline & p10 & 24.7 & 27.1 & 78.6 & 30.8 & \\
\hline & p90 & 181.0 & 308.5 & 372.3 & 379.7 & \\
\hline \multirow[t]{4}{*}{$\mathrm{CD} 14^{+}$} & Median & 195.4 & 210.9 & 202.6 & 165.4 & \multirow[t]{4}{*}{0.769} \\
\hline & IQR & 122.2 & 154.6 & 167.8 & 162.5 & \\
\hline & p10 & 128.4 & 132.1 & 91.6 & 81.0 & \\
\hline & p90 & 295.4 & 315.6 & 311.8 & 301.3 & \\
\hline \multirow[t]{4}{*}{$\mathrm{CD} 14^{+} \mathrm{CD} 80^{+}$} & Median & 185.6 & 195.6 & 180.4 & 147.1 & \multirow[t]{4}{*}{0.769} \\
\hline & IQR & 128.8 & 142.2 & 166.6 & 168.0 & \\
\hline & $\mathrm{p} 10$ & 109.2 & $115 / 0$ & 77.4 & 71.3 & \\
\hline & $\mathrm{p} 90$ & 289.6 & 279.1 & 292.6 & 291.9 & \\
\hline \multirow[t]{4}{*}{$\mathrm{CD}_{14}{ }^{+} \mathrm{CD} 86^{+}$} & Median & 186.3 & 197.8 & 184.3 & 155.1 & \multirow[t]{4}{*}{0.737} \\
\hline & IQR & 113.3 & 137.9 & 159.3 & 168.3 & \\
\hline & $\mathrm{p} 10$ & 109.2 & 116.0 & 78.0 & 67.9 & \\
\hline & p90 & 264.1 & 276.5 & 284.6 & 286.0 & \\
\hline \multirow[t]{4}{*}{$\mathrm{CD}^{-} \mathrm{CD}^{-} 6^{+}$} & Median & $109.8^{\mathrm{a}}$ & $91.0^{\mathrm{ab}}$ & $70.7^{b}$ & $85.2^{b}$ & \multirow[t]{4}{*}{0.017} \\
\hline & IQR & 72.6 & 45.3 & 90.6 & 91.3 & \\
\hline & $\mathrm{p} 10$ & 61.9 & 61.4 & 27.1 & 20.7 & \\
\hline & p90 & 158.3 & 124.6 & 163.5 & 134.4 & \\
\hline
\end{tabular}


Table 5. Phagocytic activity of neutrophils and monocytes analysed immediately (day 0) or after blood storage at room temperature for 24, 48 or 72 hours (day 1, 2 and 3, respectively) prior to analysis. Data are median (IQR) for $\mathrm{n}=10$ per time point. $\mathrm{P} 10$ and $\mathrm{p} 90$ represent $10^{\text {th }}$ and $90^{\text {th }}$ percentile values. $\mathrm{P}$ value is from the Friedman's test. Where pairwise comparisons were made, median values not sharing a common letter are different.

\begin{tabular}{|c|c|c|c|c|c|c|}
\hline Parameter & Statistics & Day 0 & Day 1 & Day 2 & Day 3 & p Value \\
\hline \multirow{4}{*}{$\begin{array}{c}\text { Percentage of } \\
\text { gated neutrophils } \\
\text { with phagocytic } \\
\text { activity }\end{array}$} & Median & 79.4 & 78.4 & 76.9 & 71.6 & \multirow[t]{4}{*}{0.086} \\
\hline & IQR & 15.1 & 41.1 & 15.3 & 18.5 & \\
\hline & $\mathrm{p} 10$ & 56.7 & 12.1 & 59.9 & 40.4 & \\
\hline & p90 & 90.3 & 90.5 & 82.9 & 80.9 & \\
\hline \multirow{4}{*}{$\begin{array}{l}\text { Mean fluorescence } \\
\text { intensity (MFI) of } \\
\text { active neutrophils }\end{array}$} & Median & $208.3^{\mathrm{a}}$ & $180.3^{\mathrm{ab}}$ & $179.4^{\mathrm{ab}}$ & $153.4^{\mathrm{b}}$ & \multirow[t]{4}{*}{0.026} \\
\hline & IQR & 141.8 & 158.7 & 71.6 & 53.5 & \\
\hline & $\mathrm{p} 10$ & 132.0 & 113.4 & 138.9 & 129.3 & \\
\hline & p90 & 323.0 & 303.1 & 222.7 & 214.8 & \\
\hline \multirow{4}{*}{$\begin{array}{c}\text { Percentage of } \\
\text { gated monocytes } \\
\text { with phagocytic } \\
\text { activity }\end{array}$} & Median & 15.7 & 18.1 & 24.8 & 22.9 & \multirow[t]{4}{*}{0.253} \\
\hline & IQR & 19.4 & 25.8 & 11.0 & 20.1 & \\
\hline & $\mathrm{p} 10$ & 8.6 & 8.2 & 14.0 & 7.3 & \\
\hline & p90 & 44.4 & 38.7 & 32.1 & 29.4 & \\
\hline \multirow{4}{*}{$\begin{array}{l}\text { Mean fluorescence } \\
\text { intensity (MFI) of } \\
\text { active monocytes }\end{array}$} & Median & 124.7 & 109.1 & 128.0 & 125.0 & \multirow[t]{4}{*}{0.696} \\
\hline & IQR & 44.1 & 61.2 & 26.5 & 44.2 & \\
\hline & $\mathrm{p} 10$ & 101.1 & 72.3 & 110.1 & 85.5 & \\
\hline & p90 & 167.4 & 159.9 & 156.3 & 170.8 & \\
\hline
\end{tabular}


Table 6. Cytokines and other immune mediators $(\mathrm{pg} / \mathrm{ml})$ measured in plasma prepared immediately (day 0$)$ or from blood stored at room temperature for 24, 48 or 72 hours (day 1, 2 and 3, respectively) prior to plasma preparation. Data are median (IQR) for $\mathrm{n}=10$ per time point. $\mathrm{P} 10$ and $\mathrm{p} 90$ represent $10^{\text {th }}$ and $90^{\text {th }}$ percentile values. P value is from the Friedman's test. Where pairwise comparisons were made, median values not sharing a common letter are different.

\begin{tabular}{|c|c|c|c|c|c|c|}
\hline $\begin{array}{l}\text { Immune } \\
\text { mediator }\end{array}$ & Statistics & Day 0 & Day 1 & Day 2 & Day 3 & $\underset{\text { Value }}{\mathbf{p}}$ \\
\hline \multirow{4}{*}{ MCP-1 } & Median & $215^{\mathrm{a}}$ & $230^{\mathrm{ac}}$ & $284^{\mathrm{bc}}$ & $348^{\mathrm{b}}$ & \multirow[t]{4}{*}{$<0.001$} \\
\hline & IQR & 125 & 148 & 202 & 254 & \\
\hline & p10 & 152 & 145 & 159 & 170 & \\
\hline & p90 & 300 & 344 & 441 & 531 & \\
\hline \multirow{4}{*}{ RANTES } & Median & $18242^{\mathrm{a}}$ & $21677^{b}$ & $22629^{b}$ & $22468^{b}$ & \multirow[t]{4}{*}{0.007} \\
\hline & IQR & 6933 & 8957 & 5590 & 4002 & \\
\hline & $\mathrm{p} 10$ & 13174 & 13430 & 18901 & 15619 & \\
\hline & p90 & 22650 & 27713 & 25238 & 25528 & \\
\hline \multirow{4}{*}{ ICAM-1 } & Median & 286827 & 298383 & 289075 & 298234 & \multirow[t]{4}{*}{0.131} \\
\hline & IQR & 179861 & 199202 & 194426 & 178524 & \\
\hline & p10 & 127603 & 131680 & 146469 & 145710 & \\
\hline & p90 & 455145 & 486453 & 469715 & 478264 & \\
\hline \multirow{4}{*}{ TNF-RII } & Median & $1896^{\mathrm{a}}$ & $2240^{\mathrm{ab}}$ & $2576^{\mathrm{bc}}$ & $2715^{\mathrm{c}}$ & \multirow[t]{4}{*}{$<0.001$} \\
\hline & IQR & 1364 & 1718 & 1910 & 1922 & \\
\hline & p10 & 1114 & 1303 & 1595 & 1675 & \\
\hline & p90 & 2563 & 3201 & 3590 & 3854 & \\
\hline \multirow{4}{*}{ IL-1ra } & Median & $565^{\mathrm{a}}$ & $992^{a b}$ & $2984^{\mathrm{bc}}$ & $6853^{c}$ & \multirow[t]{4}{*}{$<0.001$} \\
\hline & IQR & 217 & 506 & 2803 & 6208 & \\
\hline & p10 & 423 & 637 & 1216 & 2058 & \\
\hline & p90 & 737 & 1380 & 5870 & 16374 & \\
\hline
\end{tabular}




\begin{tabular}{|c|c|c|c|c|c|c|}
\hline \multirow{4}{*}{ MIP-1 $\alpha$} & Median & $1922^{\mathrm{a}}$ & $2025^{\mathrm{b}}$ & $2064^{b c}$ & $2037^{b c}$ & \multirow[t]{4}{*}{0.036} \\
\hline & IQR & 100 & 267 & 130 & 162 & \\
\hline & $\mathrm{p} 10$ & 1855 & 1808 & 1910 & 1861 & \\
\hline & p90 & 2023 & 2156 & 2161 & 2148 & \\
\hline \multirow{4}{*}{ E selectin } & Median & $19700^{\mathrm{a}}$ & $20143^{\mathrm{a}}$ & $20934^{\mathrm{b}}$ & $20238^{\mathrm{ab}}$ & \multirow[t]{4}{*}{0.048} \\
\hline & IQR & 8124 & 9838 & 8897 & 8161 & \\
\hline & $\mathrm{p} 10$ & 14989 & 14744 & 15292 & 15312 & \\
\hline & p90 & 24462 & 26167 & 25760 & 25373 & \\
\hline \multirow{4}{*}{ IL-18-Bра } & Median & $272^{\mathrm{a}}$ & $286^{\mathrm{ac}}$ & $303^{b}$ & $296^{b c}$ & \multirow[t]{4}{*}{0.014} \\
\hline & IQR & 260 & 247 & 298 & 286 & \\
\hline & p10 & 113 & 108 & 116 & 121 & \\
\hline & p90 & 417 & 443 & 462 & 438 & \\
\hline \multirow{4}{*}{ VCAM-1 } & Median & $942281^{\mathrm{a}}$ & $906475^{a}$ & $820782^{\mathrm{ac}}$ & $822353^{b c}$ & \multirow[t]{4}{*}{0.024} \\
\hline & IQR & 657283 & 549098 & 545903 & 553687 & \\
\hline & $\mathrm{p} 10$ & 540240 & 539761 & 478755 & 456481 & \\
\hline & p90 & 1319270 & 1274610 & 1100440 & 1073120 & \\
\hline \multirow{4}{*}{ IL-8 } & Median & $6.05^{\mathrm{a}}$ & $410.47^{\mathrm{ab}}$ & $1125.46^{\mathrm{b}}$ & $2336.31^{b}$ & \multirow[t]{4}{*}{$<0.001$} \\
\hline & IQR & 3.22 & 346.44 & 1185.03 & 3239.56 & \\
\hline & $\mathrm{p} 10$ & 3.68 & 37.76 & 126.12 & 381.08 & \\
\hline & P90 & 7.87 & 696.91 & 2652.38 & 5836.65 & \\
\hline \multirow{4}{*}{ IL-10 } & Median & $0.55^{\mathrm{a}}$ & $0.65^{\mathrm{ab}}$ & $1.74^{\mathrm{bc}}$ & $3.57^{\mathrm{c}}$ & \multirow[t]{4}{*}{$<0.001$} \\
\hline & IQR & 0.48 & 1.14 & 1.66 & 2.26 & \\
\hline & p10 & 0.18 & 0.51 & 1.24 & 1.90 & \\
\hline & P90 & 0.87 & 2.56 & 4.20 & 4.73 & \\
\hline
\end{tabular}




\begin{tabular}{|c|c|c|c|c|c|c|}
\hline \multirow{4}{*}{ IL-6 } & Median & $1.02^{\mathrm{a}}$ & $4.13^{b}$ & $26.13^{b c}$ & $27.90^{\mathrm{c}}$ & \multirow[t]{4}{*}{$<0.001$} \\
\hline & IQR & 0.41 & 7.03 & 19.41 & 54.76 & \\
\hline & p10 & 0.78 & 1.12 & 2.07 & 2.55 & \\
\hline & P90 & 1.35 & 11.00 & 67.58 & 70.35 & \\
\hline \multirow{4}{*}{ TNF- $\alpha$} & Median & $6.53^{\mathrm{a}}$ & $8.07^{\mathrm{ab}}$ & $8.445^{\mathrm{bc}}$ & $11.17^{\mathrm{c}}$ & \multirow[t]{4}{*}{$<0.001$} \\
\hline & IQR & 2.67 & 6.24 & 7.75 & 5.05 & \\
\hline & $\mathrm{p} 10$ & 4.20 & 4.62 & 5.80 & 6.56 & \\
\hline & P90 & 8.12 & 15.97 & 21.73 & 15.97 & \\
\hline
\end{tabular}


Table 7. Cytokines and immune mediators $(\mathrm{pg} / \mathrm{mL})$ measured in supernatants of whole blood cultures set up immediately (day 0) or with blood stored at room temperature for 24, 48 or 72 hours (day 1, 2 and 3, respectively) prior to culture. Data are median (IQR) for $\mathrm{n}=10$ per time point. $\mathrm{P} 10$ and $\mathrm{p} 90$ represent $10^{\text {th }}$ and $90^{\text {th }}$ percentile values. $\mathrm{P}$ value is from the Friedman's test. Where pairwise comparisons were made, median values not sharing a common letter are different.

\begin{tabular}{|c|c|c|c|c|c|c|}
\hline $\begin{array}{l}\text { Immune } \\
\text { mediator }\end{array}$ & Statistics & Day 0 & Day 1 & Day 2 & Day 3 & p Value \\
\hline \multicolumn{7}{|c|}{ Unstimulated Whole Blood Cultures } \\
\hline \multirow{4}{*}{ TNF- $\alpha$} & Median & $1.20^{\mathrm{ac}}$ & $0.70^{\mathrm{a}}$ & $1.20^{\mathrm{ac}}$ & $2.62^{b c}$ & \multirow[t]{4}{*}{$<0.001$} \\
\hline & IQR & 1.02 & 1.02 & 2.44 & 3.94 & \\
\hline & p10 & 0.18 & 0.18 & 0.18 & 0.18 & \\
\hline & p90 & 1.20 & 1.58 & 3.97 & 9.78 & \\
\hline \multirow{4}{*}{ IL-6 } & Median & 2.47 & 1.82 & 2.47 & 4.10 & \multirow[t]{4}{*}{0.074} \\
\hline & IQR & 4.87 & 2.58 & 7.75 & 13.81 & \\
\hline & p10 & 0.37 & 0.28 & 0.37 & 2.59 & \\
\hline & p90 & 7.00 & 4.23 & 13.74 & 21.36 & \\
\hline \multicolumn{7}{|c|}{ PGN stimulated Whole Blood Cultures } \\
\hline \multirow{4}{*}{ IL-10 } & Median & 76.59 & 58.64 & 55.21 & 53.75 & \multirow[t]{4}{*}{0.516} \\
\hline & IQR & 120.10 & 55.12 & 84.06 & 29.60 & \\
\hline & p10 & 29.23 & 20.45 & 29.59 & 38.68 & \\
\hline & p90 & 169.46 & 110.08 & 143.78 & 78.04 & \\
\hline \multirow{4}{*}{ TNF- $\alpha$} & Median & $678.40^{\mathrm{a}}$ & $849.68^{\mathrm{ab}}$ & $866.18^{b}$ & $1181.41^{\mathrm{b}}$ & \multirow[t]{4}{*}{0.024} \\
\hline & IQR & 1179.97 & 1344.86 & 1323.12 & 1182.98 & \\
\hline & $\mathrm{p} 10$ & 261.40 & 144.93 & 199.22 & 721.63 & \\
\hline & p90 & 2072.85 & 1803.76 & 3472.82 & 2652.69 & \\
\hline IL-6 & Median & 4251.81 & 5396.96 & 3960.04 & 4772.28 & 0.615 \\
\hline
\end{tabular}




\begin{tabular}{|c|c|c|c|c|c|c|}
\hline & IQR & 5090.06 & 5291.98 & 3647.04 & 4732.04 & \\
\hline & p10 & 2179.15 & 1101.83 & 2838.47 & 2880.42 & \\
\hline & p90 & 9681.22 & 7813.54 & 8429.84 & 8409.11 & \\
\hline \multirow{4}{*}{ IL-12p70 } & Median & 59.36 & 49.18 & 70.05 & 80.23 & \multirow[t]{4}{*}{0.073} \\
\hline & IQR & 103.87 & 41.75 & 80.53 & 68.62 & \\
\hline & $\mathrm{p} 10$ & 15.14 & 31.48 & 31.48 & 33.81 & \\
\hline & p90 & 119.01 & 105.62 & 174.15 & 141.39 & \\
\hline \multirow{4}{*}{ IL-1 $\beta$} & Median & 452.22 & 431.40 & 517.95 & 1108.34 & \multirow[t]{4}{*}{0.062} \\
\hline & IQR & 607.75 & 536.95 & 697.83 & 1197.59 & \\
\hline & $\mathrm{p} 10$ & 213.66 & 99.79 & 343.74 & 490.78 & \\
\hline & p90 & 1552.32 & 1212.89 & 2886.73 & 2106.87 & \\
\hline \multicolumn{7}{|c|}{ LPS stimulated Whole Blood Cultures } \\
\hline \multirow{4}{*}{ IL-10 } & Median & $230.27^{\mathrm{a}}$ & $114.41^{\mathrm{ab}}$ & $64.16^{\mathrm{bc}}$ & $32.43^{\mathrm{c}}$ & \multirow[t]{4}{*}{$<0.001$} \\
\hline & IQR & 167.85 & 136.22 & 53.32 & 25.25 & \\
\hline & p10 & 135.76 & 88.79 & 28.79 & 15.87 & \\
\hline & p90 & 368.12 & 277.69 & 87.41 & 50.23 & \\
\hline \multirow{4}{*}{ TNF- $\alpha$} & Median & $2725.77^{\mathrm{a}}$ & $2060.80^{\mathrm{a}}$ & $1074.86^{\mathrm{ab}}$ & $1212.13^{\mathrm{b}}$ & \multirow[t]{4}{*}{$<0.001$} \\
\hline & IQR & 1905.24 & 1911.75 & 1622.09 & 1122.11 & \\
\hline & p10 & 962.64 & 863.85 & 509.42 & 614.25 & \\
\hline & p90 & 3824.45 & 3315.12 & 3207.80 & 2297.79 & \\
\hline \multirow{4}{*}{ IL-6 } & Median & $7152.83^{\mathrm{ac}}$ & $7032.92^{\mathrm{a}}$ & $4295.17^{b c}$ & $3707.46^{b}$ & \multirow[t]{4}{*}{$<0.001$} \\
\hline & IQR & 4471.53 & 4881.58 & 4057.13 & 3956.71 & \\
\hline & $\mathrm{p} 10$ & 3668.16 & 3794.04 & 3184.78 & 2244.92 & \\
\hline & P90 & 10123.17 & 10243.66 & 9718.23 & 8227.96 & \\
\hline \multirow{2}{*}{ IL-12p70 } & Median & $175.90^{\mathrm{a}}$ & $146.89^{\mathrm{a}}$ & $62.97^{b}$ & $96.14^{\mathrm{b}}$ & \multirow[t]{2}{*}{$<0.001$} \\
\hline & IQR & 58.59 & 99.10 & 91.11 & 37.29 & \\
\hline
\end{tabular}




\begin{tabular}{|c|c|c|c|c|c|c|}
\hline & $\mathrm{p} 10$ & 74.42 & 69.63 & 26.47 & 67.55 & \\
\hline & P90 & 210.53 & 240.18 & 203.72 & 151.26 & \\
\hline \multirow{4}{*}{ IL-1 $\beta$} & Median & $4993.02^{\mathrm{a}}$ & $3833.54^{\mathrm{a}}$ & $2428.44^{\mathrm{b}}$ & $2195.63^{b}$ & \multirow[t]{4}{*}{$<0.001$} \\
\hline & IQR & 2293.11 & 2088.31 & 2065.54 & 1457.10 & \\
\hline & $\mathrm{p} 10$ & 2867.84 & 1766.94 & 1585.59 & 1382.90 & \\
\hline & P90 & 6736.58 & 6132.85 & 5295.95 & 3726.75 & \\
\hline \multicolumn{7}{|c|}{ PHA stimulated Whole Blood Cultures } \\
\hline \multirow{4}{*}{ IFN- $\gamma$} & Median & $183.45^{\mathrm{a}}$ & $25.03^{\mathrm{a}}$ & $5.45^{\mathrm{b}}$ & $4.67^{\mathrm{b}}$ & \multirow[t]{4}{*}{$<0.001$} \\
\hline & IQR & 299.05 & 130.12 & 22.38 & 18.79 & \\
\hline & p10 & 38.50 & 5.54 & 2.53 & 2.30 & \\
\hline & P90 & 508.534 & 245.767 & 39.554 & 10040.67 & \\
\hline \multirow{4}{*}{ TNF- $\alpha$} & Median & $383.33^{\mathrm{a}}$ & $443.91^{\mathrm{ab}}$ & $340.59^{b}$ & $290.04^{b}$ & \multirow[t]{4}{*}{0.024} \\
\hline & IQR & 417.92 & 613.51 & 334.39 & 311.15 & \\
\hline & p10 & 124.33 & 145.98 & 115.04 & 117.81 & \\
\hline & P90 & 790.41 & 1079.01 & 834.40 & 609.77 & \\
\hline
\end{tabular}




\section{Bibliography}

Albers, R., Antoine, J.-M., Bourdet-Sicard, R., et al. (2007). Markers to measure immunomodulation in human nutrition intervention studies. Br J Nutr, 94(03), 452-481. doi: https://doi.org/10.1079/BJN20051469

Albers, R., Bourdet-Sicard, R., Braun, D., et al. (2013). Monitoring immune modulation by nutrition in the general population: identifying and substantiating effects on human health. Br J Nutr, 110 Suppl 2, S1-30. doi: https://doi.org/10.1017/S0007114513001505

Bohuslav, J., Kravchenko, V., Parry, G., et al. (1998). Regulation of an essential innate immune response by the p50 subunit of NF-kappaB. J Clin Invest, 102, 1645-1652. doi: https://doi.org/10.1172/JCI3877

Defang, G. N., Martin, N. J., Burgess, T. H., et al. (2012). Comparative analysis of hemagglutination inhibition titers generated using temporally matched serum and plasma samples. PLoS One, 7(12), e48229. doi: https://doi.org/10.1371/journal.pone.0048229

Jackman, R., Utter, G., Heitman, J., et al. (2011). Effects of blood sample age at time of separation on measured cytokine concentrations in human plasma. Clin Vaccine Immunol, 18(2), 318-326. doi: 10.1128/CVI.00465-10

Kohler, G., \& Joly, A. (1997). The involvement of an LPS Inducible IkB Kinase in Endotoxin Tolerance. Biochem Biophys Res Commun, 232, 602-607. doi: https://doi.org/10.1006/bbrc.1997.6337

Kwan, B., Roberts, R., Ank, B., et al. (1996). Effects of Anticoagulant, Serum, and Temperature on the Natural Killer Activity of Human Peripheral Blood Mononuclear Cells Stored Overnight. Clin Diagn Lab Immunol, 3, 260-264. doi: http:/1071-412X/96/\$04.00+0

LaRue, K., \& McCall, C. (1994). A labile transcriptional repressor modulates endotoxin tolerance. J Exp Med, 180, 2269-2275. doi: https://doi.org/10.1084/jem.180.6.2269

Plociennikowska, A., Hromada-Judycka, A., Borzecka, K., et al. (2015). Co-operation of TLR4 and raft proteins in LPSinduced pro-inflammatory signaling. Cell Mol Life Sci, 72(3), 557-581. doi: 10.1007/s00018-014-1762-5

Tecchio, C., Micheletti, A., \& Cassatella, M. A. (2014). Neutrophil-derived cytokines: facts beyond expression. Front Immunol, 5, 508. doi: 10.3389/fimmu.2014.00508

Thornthwaite, J., Rosenthal, P., Vazquez, D., et al. (1984). The effects of anticoagulant and temperature on the measurements of helper and suppressor cells. Diagn Immunol., 2(3), 167-174. doi:

https://www.ncbi.nlm.nih.gov/pubmed/6238755 